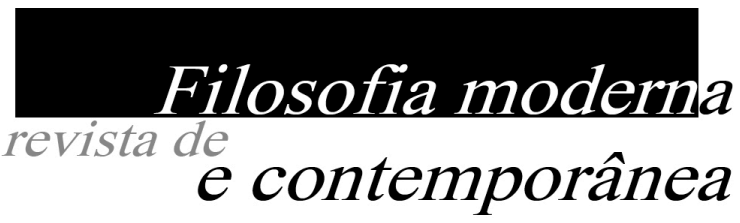

\title{
Crença no mundo exterior: mente e objetividade em Hume ${ }^{1}$ \\ Andrea Cachel ${ }^{2}$
}

Resumo: Este artigo pretende analisar a discussão humeana sobre a crença nos corpos, apresentada na seção Do ceticismo quanto aos sentidos, do Tratado da Naturez̧a Humana, e na seção Da Filosofia Acadêmica on Cética, das Investigações acerca do Entendimento Humano. Em especial, ele procura mostrar que a inteligibilidade da existência externa funda-se em uma atividade da mente, por meio da atuação da imaginação, e pressupõe uma resignificação dos conceitos de mente e de percep̧cão. Para tanto, parte da exposição de alguns pressupostos da questão, tais como a tradução da existência externa nas noções de continuidade e distinção, a separação entre sistema vulgar e filosófico e o significado da rejeição dos sentidos e da razão como possíveis causas da crença no mundo.

Palavras-chave: percepção, mente, objeto, ceticismo, imaginação, crença

Abstract: This article aims to analyse Hume's discussion about belief in bodies, present in the section Of scepticism with regard to the senses, of Treatise of Human Nature, and in the section Of the academical or sceptical Philosophy, of Enquiries concerning Human Understanding. Particularly, its purpose is to show that the intelligibility of external existence is based on an activity of mind, through the work of the imagination, and requires a redefinition of the concepts of mind and perception. For this purpose, this article explains some assumptions of the question, such as the translation of external existence in the idea continuity and distinction, the separation between vulgar and philosophical system and the rejection of the senses and the reason as possible causes of belief in external world.

Keywords: perception, mind, object, skepticism, imagination, belief.

\footnotetext{
${ }^{1}$ Este texto é parte da Dissertação de Mestrado, defendida no Programa de Pós-Graduação da UFPR: CACHEL, 2005.

2 Doutora em Filosofia pela Universidade de São Paulo, atualmente faz pós-doutorado na Universidade de Campinas, é professora da Universidade Federal de Juiz de Fora.
} 
A discussão sobre a objetividade de nossas percepções ainda é um dos temas que figuram no debate acerca do conhecimento. Como sabemos, o sentido dado pela filosofia moderna a essa discussão, ainda que possa ter sofrido uma série de alterações, define alguns dos rumos posteriores da temática. A filosofia humeana, nesse contexto, apresenta elementos bastante centrais para os percursos subsequentes da análise quanto às relações entre percepção e objetividade. Em especial, sua discussão sobre a crença no mundo exterior, apresentada principalmente na seção do Tratado intitulada Do Ceticismo quanto aos Sentidos (HUME, 2000: 125-144), traz novas nuances ao debate. Nela Hume irá mostrar em que medida a crença na noção de objeto implica uma ruptura com teorias representativas e a exigência de uma maior atividade da mente. Caberá, segundo ele, a princípios da imaginação forjar a ideia de que há um mundo exterior, que é causa de determinadas percepções. Nesse sentido, a objetividade aparecerá, na filosofia humeana, como uma ficção necessária, possível a partir de uma redefinição do conceito de mente e, em consequência, de conteúdo mental. Sobretudo, em Hume a tendência da imaginação de estender a regularidade observada - base também da própria relação de causa e efeito, e, portanto, da própria racionalidade experimental será colocada como o núcleo da suposição, que adquire vivacidade, de que a algumas das nossas percepções corresponde um mundo objetivo.

A discussão humeana quanto à crença no mundo exterior parte de dois cortes importantes, apresentados logo no início da seção sobre o ceticismo em relação aos sentidos, no Tratado. Em primeiro lugar, Hume deixa claro que o problema a ser resolvido no texto é saber que causas nos induzem a 


\section{Crença no mundo exterior: mente e objetividade em Hume}

crer na existência dos corpos e não responder se os corpos existem ou não (HUME, 2000: 125). Mais adiante esclarece que a crença nos corpos será traduzida pela crença em uma existência contínua e distinta, ou conforme define, a crença em que os objetos existem mesmo quando não percebidos, são independentes da situação no sujeito e exteriores ao mesmo (HUME, 2000: 125-126). Sendo assim, trata-se de ponderar como atribuímos continuidade e distinção a alguns conteúdos mentais e em que medida essa atribuição pode adquirir a força e vivacidade definidoras de uma crença.

Inicialmente é na sexta seção, da segunda parte do Tratado (HUME, 2000: 48-49), que podemos encontrar os subsídios para compreender melhor o ponto de partida da exposição humeana. No contexto das análises das ideias de existência e existência externa, ${ }^{3}$ Hume sustenta que a noção de objetos externos como existências especificamente diferentes das percepções os tornam ininteligíveis. Tal discussão parte das considerações sobre a ideia de existência, sendo a defesa humeana da indisssociabilidade da ideia de existência e de objeto existente a permeadora da sua opinião sobre a crença nos corpos. Na concepção da filosofia humeana, não haveria distinção entre a ideia de existência e a de objeto, ou seja, a existência não poderia ser abstraída da ideia de objeto existente: "a ideia de existência é exatamente a mesma que a ideia daquilo que concebemos como existente [...] e a ideia de existência,

\footnotetext{
${ }^{3}$ Desde já cabe ressaltar que, embora a noção de existência externa seja analisada no contexto da discussão sobre espaço e tempo, existência externa não parece significar, nesse momento do texto, existência espacial. Hume afirmará que a crença nos objetos externos significa crer que alguns objetos da percepção são contínuos, independentes e têm uma situação espacial externa, assim, "existência externa" não representa apenas uma existência que tenha uma situação espacial externa, já que esse será apenas um dos seus elementos e não sua definição como um todo.
}

\section{Revista de Filosofia Moderna e Contemporânea$$
\text { Brasília, no 1, ano 1, } 2013 .
$$ 
quando conjugada com a ideia de um objeto, não acrescenta nada a esta"( HUME, 2000: 48). Em outros termos, a existência não poderia ser considerada como um predicado da ideia de objeto. ${ }^{4}$ Além disso, na visão da filosofia humeana, todos os objetos da mente seriam concebidos como existentes: "Não há impressão ou ideia de qualquer espécie, de que tenhamos alguma consciência ou memória, que não seja concebida como existente." (HUME, 2000: 48). Nesse sentido, a atribuição de existência a um objeto concebido apenas especificaria algo que já faria parte da ideia de todo objeto e, nesse sentido, essa atribuição não estabeleceria qualquer remissão à objetividade, além de não ser o que diferenciaria os objetos nos quais cremos daqueles em que não cremos.

E a indissociabilidade entre ideia de existência e ideia de objeto determinaria, ainda, a ininteligibilidade de existências especificamente diferentes das percepções. Se a existência de um objeto não seria o que possibilitaria uma remissão à objetividade, por outro lado, tal remissão poderia ser garantida se fosse possível conceber a existência externa de um objeto, ou seja, se a existência externa do objeto fosse inteligível. É justamente isso que Hume procura negar, em relação à noção de objetos externos como existências especificamente diferentes das percepções, estando implicitamente na base dessa negação o pressuposto de que também a ideia de existência externa não pode ser diferente da ideia de objeto externo. É partindo desse pressuposto que ele, aplicando o princípio da cópia à noção de objetividade

\footnotetext{
${ }^{4}$ Nas palavras de CESCATO (2002: 175) "Hume está afirmando em seu vocabulário da teoria das ideias que a existência não é um predicado atribuível quer analítica quer sinteticamente ao sujeito do juízo". Dessa mesma opinião é PEARS (1990:34). Para uma opinião diferente ver WILSON F (1991). 


\section{Crença no mundo exterior: mente e objetividade em Hume}

em questão, conclui que se os objetos externos são considerados existências especificamente diferentes das percepções são ininteligíveis. Afirmar a inteligibilidade dessa existência exigiria que fosse possível concebê-la. O princípio da cópia, entretanto, mostraria o contrário. Segundo ele, ideias seriam cópias de impressões, as quais se definem, por sua vez, como percepções da mente. Em outras palavras, o universo da imaginação seria inteiramente composto por percepções da mente: "Odiar, amar, pensar, sentir, ver - tudo isso é senão perceber" (HUME, 2000: 48). Toda ideia, portanto, seria sempre percepção, o que tornaria a concepção de existências a elas diferentes em natureza impossível. Em contrapartida, esse sentido determinado de existência externa tornar-se-ia ininteligível.

Em virtude da ininteligibilidade dessa noção de existência externa, na visão de Hume, as únicas questões inteligíveis acerca da crença nos corpos seriam as pertinentes à crença na continuidade e distinção dos objetos. $\mathrm{O}$ autor reconhece que a crença nos corpos ou objetos externos é universal e busca, principalmente na seção acerca do ceticismo quanto aos sentidos, no Tratado, explicar as causas dessa crença. Evidentemente o problema analisado por Hume não é a existência dos objetos enquanto objetos percebidos, portanto, enquanto percepções. A discussão existente na crença nos corpos é, mais propriamente, a crença na existência externa ou no objeto externo, cuja noção Hume procura esclarecer. ${ }^{5}$

\footnotetext{
${ }^{5}$ Como em nosso entendimento o problema em questão é o de uma noção inteligível de existência externa, não podemos deixar de nos referir, em alguns momentos, à crença nos corpos como a "crença nos objetos externos", embora parecesse mais adequado nos referir sempre à temática como "crença nos corpos", expressão utilizada por Hume no início da seção sobre o ceticismo em relação aos sentidos. Consideramos, entretanto, que o texto humeano
}

\section{Revista de Filosofia Moderna e Contemporânea$$
\text { Brasília, no 1, ano 1, } 2013 .
$$ 
Concebemos nossos objetos como existentes e a crença nos objetos concebidos deve-se sempre à maior força e vivacidade dessa concepção, força essa decorrente das impressões originadoras da ideia, nos termos da teoria da crença humeana. A externalidade desses objetos envolve mais que a sua concepção enquanto percepções e Hume procura a noção que representa esse "algo mais", a qual, avivada, receba assentimento e constitua a nossa crença nos objetos externos. Como não seria possível ter ideia de existências especificamente diferentes das percepções, as noções escolhidas são as de continuidade e distinção. Hume parece entender haver apenas duas noções possíveis de existência externa, quais sejam, a de algo especificamente diferente das percepções ou a de existências contínuas e distintas. Como a primeira seria ininteligível, restaria investigar a origem da última, na qual, segundo Hume, não se estabeleceria uma diferença de natureza entre objetos e percepções, mas sim apenas uma diferença quanto à atribuição de relações, conexões e durações diferentes aos objetos. ${ }^{6}$

$\mathrm{O}$ mais longe que podemos chegar no que diz respeito à concepção de objetos externos, quando se os supõe especificamente diferentes de nossas percepções, é formar deles uma ideia

permite a equivalência entre a noção de "corpos" e de "objeto" e que, portanto, ao fazermos isso não cometemos nenhuma incorreção. Entretanto, sempre que não for absolutamente necessária a mudança, nos referiremos à questão como "crença nos corpos", a fim de manter uma unidade no texto.

${ }^{6}$ É difícil precisar que diferenças são, para Hume, específicas. Concordamos com STRAWSON (1997: 48-58), WRIGHT (1995: 231) e YOLTON (1990:163), que afirmam que no caso da dupla existência não há uma diferença especifica, tendo em vista a postulação de uma absoluta semelhança de aspecto entre o suposto objeto externo e a percepção causada por ele. Parece ser esse o entendimento que podemos ter da afirmação de Hume de que as diferenças nas conexões, relações e durações não são específicas. Ademais, em outro momento do seu texto, Hume caracteriza o sistema da dupla existência como a suposição de que há uma existência semelhante às percepções em sua natureza, mas diferente por ser contínua e distinta (HUME, 2000: 141). Isso indica, como observam os autores anteriormente citados, que no sistema da dupla existência há apenas a postulação de uma diferença numérica entre objetos e percepções.

Revista de Filosofia Moderna e Contemporânea 


\section{Crença no mundo exterior: mente e objetividade em Hume}

relativa, sem pretender compreender os objetos relacionados. Falando de um modo geral, nós não supomos que sejam especificamente diferentes; apenas atribuímos a eles relações, conexões e durações diferentes. (HUME, 2000: 49)

De certa forma, implicitamente a exigência é a apresentação de uma noção concebível de existência ou objeto externo. Essa é a noção em questão na discussão sobre a crença nos corpos. E é a necessidade de conceptibilidade da noção que represente nossa ideia de existência externa que faz a discussão sobre a crença nos corpos passar a ser a pergunta quanto às causas da crença nas existências contínuas e distintas. Hume parece indicar que a ideia de uma existência externa só pode ser a ideia de que objetos com a mesma natureza que as percepções que concebemos existem externamente. A identidade entre as ideias de existência e objeto faz que a ideia de existência externa deva ser equivalente à ideia de um objeto externo. Um objeto externo tanto pode ser especificamente diferente das percepções ou a elas semelhante (ou idêntico) em sua natureza. Como, para Hume, existências especificamente diferentes das percepções são inconcebíveis, só se pode ter uma ideia ou noção de existência externa quando se tem ideia de que objetos iguais ou semelhantes em natureza às impressões existem externamente. Tendo em vista que, em sua opinião, dizer que esses objetos existem externamente significa afirmar que eles têm uma existência distinta da percepção e existem mesmo quando não percebidos, toda a sua análise consiste, mais propriamente, na busca pela origem da atribuição de continuidade e distinção a alguns objetos que concebemos ou a objetos semelhantes em natureza a esses, dependendo da

\section{Revista de Filosofia Moderna e Contemporânea \\ Brasília, no 1, ano 1, 2013.}


forma como se qualifica os conteúdos da sensação, respectivamente, forma vulgar ou filosófica, como veremos adiante.

É por isso que a discussão sobre o ceticismo quanto aos sentidos consistirá na investigação de como as noções de continuidade e distinção dos objetos se tornam objetos do nosso pensamento, para, na seqüência, examinar como cremos nessas noções, ou seja, como esses objetos do nosso pensamento se tornam vivazes. O recorte estabelecido pela filosofia humeana, portanto, já configura um sentido específico de objetividade e, de certo modo, ao procurar inicialmente explicar a inteligibilidade do conteúdo mental que é base da crença, desloca a temática do acesso ao mundo objetivo para a discussão quanto aos princípios e processos da mente envolvidos no trabalho de objetivação de certas percepções. Já aqui, no recorte dado ao problema, enuncia-se a prefiguração de um maior espaço de atividade da mente, aspecto que nos parece quase inaugural da filosofia humeana.

Isso fica ainda mais claro tendo em vista o fato de que Hume irá fundar a inteligibilidade das noções de continuidade e distinção das percepções na pressuposição de uma identidade entre percepção e objeto. Tanto o Tratado quanto as Investigações acabam por tematizar a questão da crença nos corpos por meio de uma diferença essencial entre a maneira vulgar e filosófica de compreender as percepções. Entre vulgo e filosofia haveria uma distinção em relação ao que aparece à mente na sensação, além de, consequentemente, distinções quanto às qualidades a ele atribuídas. O sistema vulgar, por um lado, suporia que as impressões sensíveis são originais e não derivadas ou são nossos únicos objetos: "quando os homens seguem esse cego e poderoso instinto da natureza, eles sempre supõem que as imagens 


\section{Crença no mundo exterior: mente e objetividade em Hume}

apresentadas pelos sentidos são os objetos externos e nunca suspeitam que essas imagens são apenas representações destes" (HUME, 1999: 201). Não haveria, para o vulgo, ou seja, para todos aqueles que não refletem sobre a temática, inclusive os próprios filósofos quando não estão exercendo sua atividade filosófica, diferença entre percepção e objeto e, dessa forma, as primeiras não seriam consideradas representativas ou derivadas dos corpos materiais. Em contrapartida, o sistema filosófico aparece como uma atuação da razão sobre a crença vulgar. Seria uma exigência óbvia da razão, aceita por qualquer um que reflete, que tudo que se torna presente à mente é percepção ou imagem, com natureza descontínua e dependente. (HUME, 2000: 201). Segundo a filosofia, portanto, os objetos presentes à mente na sensação não seriam os objetos originais, ao contrário do entendimento vulgar.

Quando pressionamos um olho com o dedo, percebemos imediatamente que todos os objetos se duplicam, e que metade deles se afasta de sua posição comum e natural. Mas como não atribuímos uma existência contínua a ambas as percepções, embora tenham a mesma natureza, percebemos com clareza que todas as nossas percepções dependem de nossos órgãos e disposição de nossos nervos e espíritos animais. Essa opinião é confirmada pelo aparente aumento ou diminuição no tamanho dos objetos, segundo sua distância; pelas aparentes alterações em sua forma; pelas mudanças em suas cor e outras qualidades, ocasionadas por doenças e indisposições; por um número infinito de outros experimentos do mesmo tipo. Tudo isso ensina que nossas percepções sensíveis não possuem uma existência distinta ou independente. (HUME, 2000: 140)

Hume sustentará que a crença na ideia de que há objetos que existem mesmo quando não percebidos e que possuem existência independente da

\section{Revista de Filosofia Moderna e Contemporânea$$
\text { Brasília, no 1, ano 1, } 2013 .
$$ 
nossa percepção será resultado da atuação da imaginação, a qual partiria do sistema vulgar. Dessa forma, a objetividade se constituiria como a atribuição de continuidade e distinção a algumas percepções, pressupostas como existências únicas. Antes de explicar como a imaginação produz isso que ele qualifica como ficção, Hume defende a impossibilidade de que a crença na existência contínua e distinta pudesse ser resultado direto da própria percepção (pelos sentidos) ou da percepção complementada pela razão, seja a partir do sistema vulgar, seja do filosófico. ${ }^{7}$ Hume procurará discutir a ideia de continuidade e distinção separadamente e, conforme esclarece, entende ser fundamental essa separação para a melhor compreensão do problema (HUME, 2000: 126). Porém, como também deixa claro, considera haver uma correlação entre continuidade e distinção, ou seja, uma implicação entre a existência contínua de um objeto e sua existência distinta e vice-versa:

Pois, se os objetos dos nossos sentidos continuam a existir, quando não são percebidos, é evidente que sua existência é independente e distinta da percepção; e vice-versa, se sua existência for independente e distinta da percepção, precisam continuar a existir, mesmo quando não percebidos. (HUME, 2000: 126).

Segundo Hume, seja tomando-se como base o sistema vulgar, seja partindo do sistema filosófico, a admissão de que os sentidos possam causar a

\footnotetext{
${ }^{7}$ Em realidade, o problema dirá respeito à continuidade e independência, tendo em vista que a externalidade será considerada não tão importante na discussão. Hume afirma: "Enquanto isso podemos observar que, quando falamos de existências reais e distintas, temos mais em vista a sua independência que a sua situação espacial externa; pensamos que um objeto tem realidade suficiente quando seu Ser é ininterrupto e independente das incessantes transformações de que temos consciência em nós mesmos"(HUME, 2000: 126). Isso parece indicar que o problema inicial acerca da matéria é uma questão acerca da objetividade e não da existência de objetos espacialmente localizados ou organizados. Dessa mesma opinião são, por exemplo, PRICE (1940: 19) e PEARS (1990:196). Um objeto externo ou espacialmente localizado deve ser também independente. Ou seja, constatando-se a impossibilidade de justificar racionalmente a noção de independência, a questão da externalidade nem se coloca.
}

Revista de Filosofia Moderna e Contemporânea 


\section{Crença no mundo exterior: mente e objetividade em Hume}

crença na continuidade dos objetos representaria a afirmação de uma contradição. Tratar-se-ia de, nas suas palavras, "supor que os sentidos continuam a operar, mesmo após terem cessado qualquer tipo de operação" (HUME, 2000: 126). Restaria, portanto, examinar se os sentidos podem dar origem à ideia da existência distinta dos objetos e é para essa hipótese que se direciona o Tratado. Particularmente, a análise se circunscreve na discussão sobre a possibilidade de que por meio da opinião vulgar os sentidos possam causar a ideia da existência distinta dos objetos. Isso porque, como vimos, na visão exposta no Tratado, a justificação da crença na continuidade e distinção dos objetos pela opinião filosófica exige a formulação do sistema da dupla existência, segundo o qual as existências contínuas e distintas são um algo diferente das percepções. Conforme Hume pondera, pela sensação tem-se acesso apenas ao que aparece à mente, portanto, a percepções. Caberia investigar apenas, em conseqüência, se, partindo da compreensão de que algumas impressões são (elas mesmas) distintas, podemos dizer que ao percebê-las formamos a noção de uma tal existência. Uma problematização da noção de eu, no entanto, indica, para Hume, a impossibilidade de que os sentidos justifiquem a ideia da distinção das percepções. Segundo o seu entendimento, a existência distinta de uma impressão significa a sua situação de externalidade em relação ao sujeito ou uma relação de independência diante das transformações nesse sujeito. Seria, dessa forma, necessária uma comparação entre o sujeito e as percepções. Entretanto, os sentidos não poderiam distinguir entre nós e os objetos externos (HUME, 2000: 126) e, portanto, não poderiam fornecer as impressões como independentes e

\section{Revista de Filosofia Moderna e Contemporânea \\ Brasília, no 1, ano 1, 2013.}


externas ao sujeito. Se a hipótese de que pelo sistema filosófico os sentidos causem a ideia da existência distinta é excluída e se os sentidos não podem fornecer as impressões, elas mesmas, como independentes e externas, segue-se que a noção da existência distinta dos objetos não pode ser ocasionada pelos sentidos.

E Hume observa, mesmo se a questão acerca da identidade pessoal pudesse ser resolvida apenas com base na sua identificação com o corpo, ainda não seria possível afirmar que os sentidos causam a ideia de existência distinta dos objetos. Para ele, aquilo que identificamos como o nosso corpo são tão somente algumas impressões, das quais não se pode afirmar se algo é ou não externo, visto que não faria sentido dizer que uma impressão é externa a outra impressão. Ademais, a externalidade ou espacialidade seria uma relação entre pontos coloridos e sólidos e, assim, determinadas qualidades não podem aparecer aos sentidos como externas ao corpo. Qualidades como sons, sabores e aromas não existiriam na extensão, ou seja, seriam incapazes de possuir a relação que define a existência espacial-externa, tendo em vista que a existência numa extensão é considerada pelo autor uma relação entre pontos coloridos e tangíveis, portanto, apenas cor e tangibilidade seriam passíveis dessa relação. Por fim, Hume argumenta que a visão não origina a ideia de distância ou exterioridade, tendo em vista que essas ideias, para serem originadas, dependeriam de raciocínio e experiência. ${ }^{8}$

\footnotetext{
${ }^{8} \mathrm{Na}$ análise sobre o espaço, Hume expõe o seguinte: "a ideia de extensão é nada senão a cópia desses pontos coloridos e da maneira como eles aparecem" (HUME, 2000: 27). E complementa, na discussão sobre qualidades primárias e secundárias, mostrando como o espaço é uma relação entre pontos coloridos e/ou sólidos (HUME, 2000: 151). Em sua opinião, a atribuição de existência espacial a sons, sabores ou aromas, deve-se a um princípio da imaginação, qual seja, a tendência de dar continuidade a uma relação. Como essas qualidades manteriam uma relação Revista de Filosofia Moderna e Contemporânea$$
\text { Brasília, no 1, ano 1, } 2013 .
$$ 


\section{Crença no mundo exterior: mente e objetividade em Hume}

No caso da independência o que se pretende evidenciar é, empregando-se um argumento já utilizado, que essa noção só pode ser objeto de uma inferência e não de uma sensação. De acordo com o Tratado, a opinião de que uma percepção é independente das transformações no sujeito ou mantém-se invariável nas mudanças de situação do sujeito que percebe (mesmo que também aqui se pudesse resolver o problema acerca da identidade pela sua corporeidade), não pode ser proveniente da simples percepção das impressões, mas sim deve ser uma conclusão tomada a partir de um raciocínio experimental. Isso porque, poderíamos pensar, partindo-se da opinião de que o que é presente à mente são os próprios objetos, deveríamos poder admitir que a percepção, ela mesma, deve ser independente das transformações do sujeito. Tal admissão, no entanto, seria dependente da realização de uma comparação entre as transformações e a variação ou não da percepção. Dessa forma, assim como a crença na sua externalidade, a crença na existência independente das percepções não pode ser originada pelos sentidos. Supor que os sentidos causam a noção de existência contínua seria contraditório, pois significaria que eles continuam a operar mesmo quando não percebemos, como já comentamos. Hume acrescenta, no Tratado, que, com relação à distinção, ideia que ele já argumentara não ser formada pelos sentidos, torna-se inconcebível supor que as impressões são sentidas como distintas. Se os sentidos apresentam todas as impressões como percepções da mente, não seria possível que eles as apresentassem como distintas. Afinal,

de causalidade (conjunção constante) e contiguidade temporal com a tangibilidade e a cor, a mente tenderia a criar a ficção de que há também uma conjunção no espaço entre essas qualidades, embora apenas a cor e a tangibilidade possam existir no espaço. (HUME, 2000:152)

\section{Revista de Filosofia Moderna e Contemporânea$$
\text { Brasília, no 1, ano 1, } 2013 .
$$ 
todas as impressões são percepções que, por sua vez, são existências dependentes e internas e devem ser sentidas dessa forma. ${ }^{9}$

E, tendo mostrado que os sentidos não podem ser considerados a origem da crença na existência contínua e distinta, Hume partirá para a discussão acerca da possibilidade ou não de fundamentarmos a crença nos objetos na razão. Contudo, também essa hipótese será rejeitada pela filosofia humeana. Alguns problemas apareceriam na tentativa de que a razão fundamentasse a crença: uma diferença na abrangência da crença, por um lado, e dos argumentos racionais, por outro; a contrariedade entre a base da crença na matéria e a razão e o fato de que não seria possível inferir a existência dos objetos partindo das percepções. O primeiro ponto não é propriamente o argumento mais forte da discussão. O segundo problema parece sim tocar no ponto exato em que razão e imaginação tornam-se incompatíveis. Haveria uma oposição entre os princípios filosóficos ou de razão e crenças naturais e, sobretudo, no caso em questão, entre a suposição de que as percepções são os próprios objetos e princípio filosófico segundo o qual as percepções não possuem existência contínua e distinta. A aplicação de um raciocínio causal nos faria concluir que percepções são descontínuas e dependentes e, portanto, não são objetos. Além disso, segundo a filosofia humeana, ainda que não se colocasse em questão a identificação entre

\footnotetext{
${ }^{9}$ PENELHUM (1975: 64) sintetiza muito bem esse argumento: "Não podemos estar enganados sobre a natureza das nossas impressões. Todas nossas impressões 'paixões, afecções, sensações, dores e prazeres', estão 'originalmente em pé de igualdade'. Quando temos paixões, não pensamos que os nossos sentidos nos apresentaram existências independentes. Então estamos errados se pensamos que o fez no caso de impressões externas". Desse modo, se o vulgo considera as qualidades primárias e secundárias como contínuas e independentes não é porque elas aparecem assim aos sentidos, ao contrário, para os sentidos elas aparecem de forma análoga às "meras percepções".
}

Revista de Filosofia Moderna e Contemporânea 


\section{Crença no mundo exterior: mente e objetividade em Hume}

percepções e objetos e se partisse do sistema vulgar, a razão ainda não poderia ser a causa da crença nos objetos, pois, nesse caso, os objetos não poderiam ser inferidos pela relação de causa e efeito. Tomando-se como base a opinião filosófica, a justificação da crença nos objetos implica a formulação do sistema da dupla existência. O problema que se coloca a esse sistema, dentre outros, é a impossibilidade de se conceber uma conjunção constante entre percepções e existências imperceptíveis, e, portanto, de se inferir existências diferentes das percepções, pela relação de causa e efeito. Assim, como os sentidos, portanto, a razão é excluída como possibilidade de ser causa da crença nos corpos.

É preciso ficarmos atentos e já perceber que a recusa de os sentidos e a razão causarem a crença na matéria indica como deverá haver uma "falsificação" da natureza das percepções, a fim de se justificar a crença nos corpos. Ademais, aqui já precisamos ser capazes de entender que desde o início a filosofia humeana pressupõe que é só partindo do sistema vulgar que a crença pode ser formada. Recusadas as hipóteses de que sentidos e razão sejam a causa da crença nos corpos, restará a Hume mostrar como a imaginação origina tal crença. E dados os limites e pressupostos estabelecidos, o Tratado deverá explicar como essa faculdade permite a atribuição de continuidade e distinção a determinadas impressões, considerando-se que para o vulgo as impressões sensíveis são os próprios objetos.

As considerações de Hume sobre a imaginação partem da separação entre impressões a que se atribuiria existência contínua e aquelas as quais mesmo o vulgo consideraria apenas internas. Em sua opinião, ainda que todas as impressões sejam, em si mesmas, internas e perecíveis, a crença vulgar

\section{Revista de Filosofia Moderna e Contemporânea}

Brasília, no 1, ano 1, 2013. 
Andrea Cachel

estabelece que parte delas existe quando não percebidas. Isso significa, para o autor, que além de um trabalho da imaginação, alguns aspectos diferenciados dessa parte das impressões contribuem para a formação da crença. Negando tanto as respostas de Locke quanto de Berkeley para a questão, ${ }^{10}$ Hume encontra na constância e coerência as qualidades das impressões que estariam aliadas à imaginação para a formação da crença nos corpos:

Estas montanhas, e casas, e árvores, que estão agora diante de meus olhos, sempre me apareceram na mesma ordem; e quando eu as perco de vista, ao fechar os olhos ou virar a cabeça, logo depois vejo que retornam a mim sem a menor alteração [...]. Esta constância, entretanto, não é tão perfeita que não possa admitir exceções bastante consideráveis. Corpos frequentemente mudam sua posição e qualidades, e depois de uma pequena ausência e interrupção, podem se tornar quase irreconhecíveis. Mas observemos que, mesmo com essas mudanças, eles preservam uma coerência, e têm uma dependência regular entre si; isso serve de fundamento a uma espécie de raciocínio causal e produz a opinião da existência contínua. Quando retorno ao meu aposento após um hora de ausência, não encontro o fogo de minha lareira na mesma situação que o deixei: mas estou acostumado a ver, em outros exemplos, a mesma alteração produzir-se no mesmo tempo, esteja eu presente ou ausente, perto ou longe. Essa coerência em suas mudanças, portanto, é também uma característica dos

\footnotetext{
${ }^{10}$ Para Locke a diferença entre sensações e outras ideias garante a possibilidade de se afirmar que há coisas externas que causam as sensações (LOCKE, 1979: 630). Ele reconhece que não há uma conexão necessária entre a existência das ideias e a existência de objetos que as causariam, mas estabelece uma conexão entre a existência desses objetos e a involuntariedade e maior força das sensações, ou seja, infere a existência dos objetos pelo fato de que as sensações são mais fortes e involuntárias (LOCKE, 1979: 632-633). Berkeley, assim como Hume, vai contra a filosofia lockeana e afirma que não se pode estabelecer uma conexão entre a maior força e involuntariedade de algumas percepções e os supostos objetos que as causariam, tendo em vista que paixões também seriam mais fortes e involuntárias, porém reconhecidamente internas (BERKELEY, 1998, p.116). Mas se Berkeley é contrário à ideia de que a força seja critério para se inferir a existência dos objetos externos, ele aponta a involuntariedade ao menos como causa da pressuposição de que há uma crença universal na matéria (BERKELEY, 1998: 122).
}

Revista de Filosofia Moderna e Contemporânea 


\section{Crença no mundo exterior: mente e objetividade em Hume}

objetos externos, assim como sua constância. (HUME, 2000: 130)

Portanto, Hume identifica em todas as impressões que se crê possuírem existência contínua uma constância nas suas aparições à mente ou, quando há mudança nessa aparição, minimamente uma coerência na mesma. Esse seria o diferencial entre impressões que o vulgo crê serem contínuas e distintas e aquelas consideradas como impressões internas. É com base nesse diferencial que a imaginação atuaria na formação da existência contínua dos objetos. Mesmo que, segundo Hume, não haja conexão perceptível entre constância ou coerência e existência contínua (HUME, 2000: 130) é quando se descobre uma dessas qualidades que se atribui continuidade às impressões. Tal atribuição, como procura mostrar o Tratado, é resultado da atuação de princípios e propensões da imaginação. Em cada um dos casos, constância ou coerência, entretanto, são diferentes aspectos da imaginação os envolvidos. Enquanto nas impressões coerentes em suas mudanças a suposição da continuidade envolve a tendência de estender a regularidade dos objetos, nas impressões constantes ela será decorrente da tendência de atribuir identidade a objetos constantes, porém interruptos.

Começando pela coerência, Hume procura evidenciar como, em impressões cujas mudanças apresentam uma certa coerência, a tendência de se preservar uma regularidade na operação dos corpos torna necessária a suposição de sua existência contínua. Segundo ele, embora uma certa regularidade exista em todas as impressões, é tão somente nos corpos materiais que se deve pressupor a existência contínua a fim de não se

\section{Revista de Filosofia Moderna e Contemporânea \\ Brasília, nº 1, ano 1, 2013.}


contrariar a regularidade. A suposição da existência contínua nos corpos ou objetos externos (ou impressões que o vulgo entende serem os próprios objetos externos), diferentemente do que ocorreria nas impressões "internas", seria um pressuposto necessário para a preservação da regularidade na experiência. Ela seria uma forma de resolver contradições existentes entre experiências distintas (HUME, 2000, p. 131). Para Hume, nesses casos, as experiências são conflitantes, caso não haja a suposição de que alguns objetos (ou percepções) existem mesmo quando não percebidos. Seria para eliminar essa contradição que se suporia a continuidade do objeto que não apareceu aos sentidos, bem como a permanência da conexão:

Notamos uma conexão entre duas espécies de objetos na sua aparição passada aos sentidos, mas não somos capazes de observar se essa conexão é perfeitamente constante, já que ao virarmos a cabeça ou fecharmos os olhos, ela pode interromperse. O que supomos nesse caso, senão que os objetos mantém sua conexão usual apesar de sua aparente descontinuidade, e que as aparições irregulares são unidas por alguma coisa a que somos insensíveis. (HUME, 2000: 131)

A suposição de existência contínua dos objetos é, pois, para Hume, uma forma de preservar a regularidade na experiência. Num certo sentido, ela decorre da reflexão sobre os eventos, ou seja, da constatação da existência de um conflito entre experiências distintas envolvendo objetos coerentes e da experiência passada de uma conexão entre os mesmos. Entretanto, a filosofia humeana procura mostrar que ela não é derivada da razão e sim da imaginação, ou seja, não é produto de um raciocínio acerca da experiência, mas da atuação, na observação da experiência, de determinados princípios e tendências da imaginação. A afirmação de que determinado objeto existe 


\section{Crença no mundo exterior: mente e objetividade em Hume}

quando não percebido significa, nessa filosofia, sustentar uma conclusão ampliativa, que vai além do que se apresenta à mente, tendo em vista que não se poderia perceber pelos sentidos ou pela memória a existência contínua de um objeto. Portanto, a suposição da existência contínua de algo exigiria uma inferência. Pela razão, a relação pertinente nesse caso seria a de causa e efeito, de forma que, para ser fundada nessa faculdade, a continuidade das impressões coerentes deveria poder ser inferida por essa relação. Na causa e efeito, a experiência de uma conjunção constante entre os objetos dá base a um hábito autorizador da inferência da existência de um dos objetos quando apenas o outro aparece. É justamente isso que faltaria no caso das experiências em questão. Reconhecendo que há efetivamente uma inferência acerca da existência contínua dos corpos e que ela não é decorrente do raciocínio causal, Hume conclui ser ela originada pela imaginação. Mais precisamente, a suposição da existência contínua dos objetos ou impressões coerentes teria como base a tendência da mente de dar continuidade a uma cadeia de pensamentos e de estender a uniformidade dos objetos:

Objetos já possuem uma certa coerência tais como aparecem aos sentidos; mas essa coerência é muito maior e uniforme se nós supomos que os objetos possuem uma existência contínua; e como a mente já vem observando uma certa uniformidade entre alguns objetos, ela naturalmente continua, até tornar a uniformidade o mais completa possível. A simples suposição da sua existência contínua basta para esse propósito e nos dá a noção de uma maior regularidade entre os objetos, do que a que vemos quando não olhamos para além dos nossos sentidos. (HUME, 2000: 131)

Revista de Filosofia Moderna e Contemporânea

Brasília, no 1, ano 1, 2013. 
Portanto, pela imaginação, a fim de se ampliar a regularidade na experiência, supor-se-ia que há algo impercebido unindo as aparições inconstantes, porém coerentes: "O que supomos nesse caso, senão que esses objetos mantém a sua conexão usual, apesar de sua aparente interrupção e que as aparições irregulares são unidas por algo a que somos insensíveis?" (HUME, 2000: 132). Para Hume, isso significaria considerar que impressões coerentes possuem existência contínua. Isso porque, embora ele não deixe explícito nesse momento, se para o vulgo não existe outra existência além da percepção, supor a existência de um algo impercebido é supor que as percepções existem impercebidas. Além disso, se não houvesse a pressuposição de uma identidade entre o que aparece aos sentidos e o objeto, dificilmente seria possível explicar por_que da não aparição de um objeto aos sentidos se seguiria a contrariedade entre experiências.

De certa forma, portanto, o primeiro passo da filosofia humeana, para os casos em que os objetos são coerentes, foi explicar como pudemos formar a noção da existência contínua dos objetos. Ou seja, procurou-se constituir o primeiro elemento da crença. A seguir, a fim de que se justifique a crença nos corpos, é fundamental mostrar como a ficção da existência contínua pode se tornar uma crença, portanto, é preciso evidenciar o processo pelo qual ela adquire sua força. Como essa ficção, fantasia ou suposição pode se tornar uma crença não fica muito claro, mas se sugere, no Tratado, que isso ocorre em virtude da própria necessidade da suposição:

E essa suposição, inicialmente inteiramente arbitrária e hipotética, adquire uma força e evidência por ser a única que me permite resolver essas contradições. Não há quase nenhum momento em minha vida em que não se me apresente um exemplo similar, e em 


\section{Crença no mundo exterior: mente e objetividade em Hume}

que eu tenha a ocasião de supor a existência contínua de certos objetos, a fim de conectar suas aparições passadas e presentes, produzindo entre elas uma união que a experiência passada me mostrou ser a adequada a suas naturezas e circunstâncias particulares. (HUME, 2000: 133)

E após explicar o surgimento da noção de existência contínua nos objetos que possuem coerência, Hume passará a analisar de que modo essa noção é inferida nos objetos constantes. Essa análise é muito mais extensa que a primeira e nela se evidencia um processo diferente do ocorrido nos objetos coerentes. ${ }^{11}$ É o problema da formação da identidade que estará em questão na constância e é basicamente nesse problema que se concentra a análise da criação, nos objetos com tal qualidade, da ficção da existência contínua. Será a tendência da mente de atribuir identidade a percepções semelhantes e constantes em sua aparição, embora interruptas, que estará na base da suposição de uma existência contínua que, afinal, responde como crença nos corpos.

A análise da crença na existência contínua dos objetos, partindo de impressões constantes, possui quatro etapas, dentre as quais a explicação da relação filosófica de identidade é a primeira. Hume procura mostrar, nesta etapa, que a identidade é uma relação estabelecida entre percepções semelhantes e invariáveis e que ela, por si só, já envolve uma ficção da mente.

\footnotetext{
${ }^{11}$ Hume inicia a análise da constância afirmando que a coerência não é suficiente para sustentar a crença na matéria (HUME, 2000: 132). Ele parece indicar, nesse sentido, um caráter complementar ou suplementar da coerência, embora não deixe claro em que sentido a coerência é insuficiente ou, por outro lado, se a constância é suficiente em todos os casos ou não. Sobre esse provável caráter complementar PRICE (1940: 38) afirma: "A Coerência pode apenas pôr os toques finais, por assim dizer, a um processo que a Constância já havia iniciado. Sem a Constância não poderíamos crer na existência contínua de qualquer objeto."
}

\section{Revista de Filosofia Moderna e Contemporânea$$
\text { Brasília, nº 1, ano 1, } 2013 .
$$ 
Segundo a filosofia humeana, quando atribuímos identidade a um objeto, indicamos uma relação entre percepções e sua permanência no tempo. Isso porque ao afirmarmos que um objeto possui identidade, dizemos que o "objeto é o mesmo que ele próprio", o que, para essa filosofia, significaria ser o mesmo em tempos distintos, ou seja, permanecer o mesmo quando há alteração no tempo (HUME, 2000: 133). A identidade, nesse sentido, envolveria uma associação de ideias, não podendo ser originada em impressões de um objeto individual ou de uma multiplicidade de objetos. Tal associação, por sua vez, implicaria uma ficção, tendo em vista a concepção humeana da ideia de tempo, a qual o interpreta como uma ideia originada por uma sucessão, ou seja, como vinculada a uma necessária sucessão entre objetos (HUME, 2000: 133). Essa ficção seria a de que "o objeto imutável participa das mudanças dos objetos coexistentes, em particular de nossas percepções". (HUME, 2000: 133). ${ }^{12}$

Mas, como Hume deixa claro na segunda etapa da discussão sobre objetos constantes, a ficção da existência contínua não surge quando há um objeto invariável e ininterrupto, embora a atribuição de identidade (que é chamada de numérica) já envolva uma ficção, mas sim da tendência de se atribuir essa identidade a objetos constantes, porém interruptos. Apenas quando há invariabilidade e ininterruptibilidade se poderia afirmar que um objeto é "o mesmo que ele próprio", no entanto, a mente teria, segundo Hume, a propensão de fazer essa afirmação mesmo para objetos apenas

\footnotetext{
${ }^{12}$ PRICE (1940: 40) apresenta um exemplo dessa ficção: "A pedra que eu observo permanece absolutamente imodificável por cinco minutos. Contudo, pequenas mudanças ocorrem ao seu redor. A grama na qual se encontra, ondula suavemente com o vento, uma folha cai, há um pingo de chuva, depois outro, um besouro passa por ela". Para outras opiniões sobre a ficção envolvida na identidade numérica: STROUD (1995: 103-104) e O'SHEA (1997).

Revista de Filosofia Moderna e Contemporânea 


\section{Crença no mundo exterior: mente e objetividade em Hume}

constantes. Tal propensão decorreria, de acordo com esse autor, da tendência de confundir ideias que causam a mesma disposição mental.

Para Hume, quando há uma constância na aparição das percepções, mesmo havendo interrupção, ocorre também uma semelhança muito grande nas aparições, ou seja, uma forte relação entre as aparições intermitentes, o que causaria uma passagem suave na mente de uma aparição à outra. Essa suavidade faria a disposição da mente ao observar um objeto apenas constante ser muito semelhante à disposição ocasionada pela observação de um objeto constante e ininterrupto. Tendo em vista a tendência da mente de confundir objetos que causam a mesma disposição, passa-se a atribuir identidade também a objetos constantes e interruptos, embora, num primeiro momento, a relação de identidade só pudesse ser aplicada a objetos constantes e ininterruptos. A noção da existência contínua desses objetos surgiria para evitar a contradição entre essa atribuição e a constatação da interrupção da aparição dessas percepções na mente, como Hume explica na terceira etapa de sua argumentação. A identidade numérica envolveria não só invariabilidade, mas também ininterruptibilidade. Ao se refletir não se poderia deixar de constatar a impossibilidade de percepções interruptas serem numericamente idênticas, embora a tendência da mente de confundir objetos que causam a mesma disposição origine a atribuição de identidade a elas. Como, na visão de Hume, não se poderia abdicar de nenhum desses aspectos, quais sejam, por um lado, a constatação da interrupção, por outro, a tendência de atribuir identidade a esses objetos, a mente criaria a ficção de que os objetos (ou percepções) constantes existem continuamente, ou seja, que uma interrupção

\section{Revista de Filosofia Moderna e Contemporânea \\ Brasília, no 1, ano 1, 2013.}


na sua aparição à mente não significa a interrupção em seu ser. Supõe-se, assim como na coerência, que há um ser contínuo preenchendo os intervalos das aparições interrompidas (HUME, 2000: 134). Em outras palavras, tendo em vista que a crença nos corpos parte do sistema vulgar, considera-se que os objetos que aparecem à mente na sensação, os quais seriam as únicas existências, existem mesmo quando não percebidos. Também aqui a extensão da regularidade observada implicitamente entra em jogo e a ficção da existência contínua serve para suprir a irregularidade inferida do ponto de vista da reflexão.

A ficção de uma existência contínua adquiriria força e vivacidade de forma diferente do padrão apresentado pela teoria da crença humeana, conforme mostra a quarta etapa da explicação humeana. Ocorreria uma transmissão da força de "impressões" da memória diretamente à ficção da existência contínua. O que diferencia a crença de uma simples ficção é a maneira mais forte pela qual uma ideia é concebida. Se cremos na existência contínua dos objetos sensíveis isso se deve à força adquirida por essa ficção. Em geral, a força é justificada por meio de uma relação (fundamentalmente de causalidade) entre uma ideia e uma impressão. No caso da existência contínua das percepções constantes ocorreria, entretanto, segundo Hume, a transmissão da força de "impressões" da memória diretamente à ficção da existência contínua. Seriam as próprias "impressões" da memória que originariam a propensão de criar essa ficção.

Como vimos, a crença nos corpos é a crença na continuidade e na distinção dos objetos sensíveis. Resta, portanto, justificar a formação da crença na distinção. Embora não haja um detalhamento nos textos humeanos 


\section{Crença no mundo exterior: mente e objetividade em Hume}

sobre a formação dessa crença, o início da seção sobre o ceticismo com relação aos sentidos, no Tratado, já dá indicações de como ela surge, ao afirmar ser impossível pensar que objeto é contínuo, mas não é independente. Isso significa a formação da ficção da existência contínua dos objetos sensíveis exige a formação da ficção da sua existência independente. É por isso que se afirma: "A inferência da constância de nossas percepções, assim como a precedente, a da coerência, dá origem à opinião da existência contínua dos corpos, que é anterior à de sua existência distinta, e produz esse último princípio" (HUME, 2000: 139). Ao se constituir, pelos princípios da imaginação, a ideia da existência contínua das percepções, forma-se também a ideia de sua distinção, novamente para evitar a contradição. É, portanto, a crença na existência contínua que origina a crença na existência distinta e, em conseqüência, justifica a crença nos corpos como um todo.

Hume estabelece como condição fundamental para a crença nos corpos a identificação entre percepções e objetos, portanto, a pressuposição da unicidade da existência. Nesse sentido, o modo pelo qual a imaginação forma a crença nos corpos é inteiramente dependente da não postulação de uma diferença entre percepções e objetos ou, em outros termos, de que se parta do sistema vulgar e não do sistema filosófico. As análises no Tratado procuram evidenciar que nem mesmo a imaginação poderia justificar o fato de inferirmos que os objetos existem se não houvesse, em algum momento, uma identificação entre percepções e objetos. Analisando de outro modo, a crença nos corpos, para a filosofia humeana a crença em uma existência contínua e

\section{Revista de Filosofia Moderna e Contemporânea}

Brasília, no 1, ano 1, 2013. 
independente, só pode ser explicada porque o vulgo não considera impressões como imagens.

Hume deixa claro que quando os filósofos inferem a existência de objetos diferentes das percepções quanto a suas conexões, relação e duração, isso só é possível se eles entendem que um conjunto de percepções é contínuo e independente, ou seja, se de um modo geral em algum momento eles entendem que percepções são contínuas e independentes. O objeto suposto pelos filósofos, nesse sentido, é sempre semelhante em natureza a algumas percepções e só pode ser considerado delas diferentes por serem contínuos e distintos, a posteriori. Inicialmente se considera algumas percepções como contínuas e distintas e posteriormente se afirma que percepções são sempre descontínuas e dependentes. A suposição de que percepções são contínuas e independentes só pode partir do sistema vulgar, portanto da suposição de que há uma única existência. Num primeiro momento, portanto, considera-se que objetos são percepções e, em virtude dessa identificação, algumas impressões devem existir mesmo quando não percebidas. E é só por que isso ocorre num primeiro momento que, em seguida, afirma-se serem as percepções contínuas e dependentes, portanto, diferentes dos objetos, mas imagens deles.

Não é por outro motivo que o sistema da dupla existência é apresentado, por Hume, como uma alternatividade entre razão e imaginação. O sistema da dupla existência, dessa forma, não seria propriamente um sistema, mas sim a oscilação entre duas opiniões sobre algumas qualidades das percepções: 


\section{Crença no mundo exterior: mente e objetividade em Hume}

Esta hipótese é a hipótese filosófica da dupla existência, das percepções e dos objetos, que agrada a nossa razão ao admitir que nossas percepções dependentes são interruptas e diferentes e ao mesmo tempo é agradável à imaginação ao atribuir uma existência contínua a outra coisa que chama de objetos. (HUME, 2000: 141).

Como só é possível inferir a existência dos objetos porque em algum momento se considera que impressões constantes e coerentes são os próprios objetos, que são contínuos, o sistema filosófico ao afirmar que percepções são imagens de objetos, atribuiu continuidade a algum conjunto de percepções, portanto, em algum momento estipulou a identidade entre essas e os objetos.

De um lado, a razão mostra que percepções são existências descontínuas e dependentes, de outro, ao se falar em objetos se pressupõe a continuidade das percepções e, pela impossibilidade de que uma existência contínua seja dependente, a sua distinção. O que a filosofia chama de objeto é algum conjunto de percepções, ao qual se atribui as características da noção de objeto. Como a crença nos corpos, formada pela imaginação, é a suposição de que percepções existem quando não percebidas e como a razão apresenta como conclusão justamente o oposto dessa suposição, o sistema da dupla existência é sempre a alternatividade entre razão e imaginação, cujas opiniões pertinentes são opostas e não podem ser conjugadas, senão sucessivamente:

Se nós estivéssemos completamente convencidos de que nossas percepções são contínuas, idênticas e independentes, nós nunca formaríamos a opinião de uma dupla existência; porque ficaríamos satisfeitos com nossa primeira suposição e não buscaríamos nada além delas. Da mesma forma, se estivéssemos completamente convencidos de que nossas percepções são dependentes, interruptas e diferentes, nós

\section{Revista de Filosofia Moderna e Contemporânea$$
\text { Brasília, no 1, ano 1, } 2013 .
$$ 
estaríamos pouco inclinados a abraçar a opinião de uma dupla existência, pois, nesse caso, nós perceberíamos claramente o erro de nossa primeira suposição de uma existência contínua e nunca mais a levaríamos em consideração. (HUME, 2000: 142)

Entretanto, é importante destacar que isso não significa que a filosofia humeana reconheça a opinião vulgar como verdadeira ou, ainda, que ela considere tanto a opinião vulgar quanto a filosófica como possivelmente verdadeiras. A intenção humeana de defender a consistência do sistema vulgar é bastante clara e direta, no Tratado. Não nos deteremos nesse ponto, mas convém destacar previamente aqui que, por meio da sua teoria da identidade pessoal, Hume sustenta a consistência da afirmação de que os objetos percebidos diretamente na sensação têm uma existência contínua. Segundo ele, o fato da mente ser um feixe de percepções, percepções essas distintas e separáveis umas das outras, garantiria a consistência da hipótese da separação de uma das percepções da mente, separação que, nesse contexto, não representaria a sua aniquilação. Da mesma forma, tendo-se em vista uma concepção da mente como um feixe de percepções e não como uma substância, conforme Hume, tornar um objeto presente à mente não significaria necessariamente a criação de um novo ser. Isso porque dessa nova concepção de mente decorreria uma nova acepção de "ser visto, ser sentido ou ser percebido", a qual possibilitaria a uma percepção estar presente ou ausente da mente sem mudar necessariamente o seu ser:

Os objetos externos são vistos, sentidos e se tornam presentes à mente, isto é, adquirem uma tal relação com o feixe de percepções que as influenciam consideravelmente, aumentando seu número com reflexões e paixões e abastecendo a memória de ideias. O mesmo ser contínuo e 


\section{Crença no mundo exterior: mente e objetividade em Hume}

ininterrupto pode, portanto, estar ora presente à mente, ora ausente, sem nenhuma mudança real ou essencial no próprio ser. Uma interrupção na aparição aos sentidos não implica necessariamente uma interrupção na existência. (HUME, 2000:142)

Uma nova concepção de mente e, em decorrência, de conteúdo mental, ${ }^{13}$ portanto, são requisitadas para dar consistência ao sistema proposto pela filosofia humeana, a fim de justificar a crença nos corpos. Sendo assim, a discussão apresentada por Hume não apenas aborda um tema clássico da filosofia moderna, mas também esboça elementos significativos de ruptura com a própria teoria representativa que lhe é peculiar. A ideia de representação, presente no que é qualificado pela filosofia humeana como "sistema da dupla existência", é dispensada enquanto explicação plausível da objetividade de nossas percepções. A crença no mundo exterior partiria de uma identificação entre objetos e percepções e de uma construção de princípios e propensões da imaginação. Nessa medida, ressaltando-se, a análise humeana da crença no mundo exterior contém rupturas com a teoria das ideias moderna e aponta - ainda que na perspectiva da constituição de ficções - para a exigência de uma maior atividade da mente no estabelecimento da objetividade de certas percepções. A distinção kantiana entre fenômeno e coisa em si certamente reconfigura a questão, dando um sentido distinto à própria ideia de validade objetiva e ao papel do entendimento na constituição da experiência. Porém, não se pode deixar de perceber que na filosofia

\footnotetext{
${ }^{13}$ Isso permite que YOLTON (1990:153) observe dois aspectos. Primeiro que, para Hume, uma única percepção simples pode satisfazer nossa noção de objeto material. Segundo que a posição de Hume é de que ser um objeto da mente não é "ser conhecido", como seria para Descartes, Arnauld, Locke e Berkeley.
}

\section{Revista de Filosofia Moderna e Contemporânea$$
\text { Brasília, no 1, ano 1, } 2013 .
$$ 
Andrea Cachel

(c) $\frac{(1) \Theta(9)}{\mathrm{BY}}$

humeana já está delineado - talvez não de modo inaugural, mas certamente com uma nova ênfase - o caminho que prioriza a participação do sujeito na constituição da objetividade.

Revista de Filosofia Moderna e Contemporânea 


\section{Crença no mundo exterior: mente e objetividade em Hume}

\section{Referências Bibliográficas}

BERKELEY, George. The Principles of Human Knowledge. Jonathan Dancy. Oxford: Oxford University Press. 1998.

CACHEL, A. A inteligibilidade da existência externa na filosofia humeana. Curitiba. 136 p. Dissertação de Mestrado em Filosofia, UFPR. 2005.

CESCATO, Maria Clara. Sintese e Discursividade na Crítica da Razão Pura de Kant. São Paulo. Tese de Doutorado em Filosofia, USP. 2002.

HUME, David. Treatise of Human Nature. David Fate Norton/ Mary Norton. Oxford: Oxford University Press. 2000.

Enquiries concerning Human Understanding. Tom L. Beauchamp. Oxford: Oxford University Press. 1999.

LOCKE, John. An Essay Concerning Human Understanding. Oxford: Oxford University. 1979.

NOXON, James. Hume's Philosophical Development: A Study of his Methods. Oxford: At the Clarendon Press. 1973.

O'SHEA, James R. "Fictitions Duration and Informative Identity in Hume's Treatise", in: Manuscrito, vol.XX, n.2, p. 145- 167. 1997.

PEARS, David. Hume's System. An Examination of the First Book of his Treatise. Oxford University Press. 1990.

PENELHUM, Terence. Hume. Londres: The Macmillan Press. 1975.

PENELHUM, Terence. "Hume on Personal Identity", in: Modern Studies in Philosophy (Hume). V.C. Cappell. Londres: University of Notre Dame Press. 1966. 
PITSON, A.E. "Hume on Primary and Secondary Qualities", in: Hume Studies, vol.VIII, n.2, pp.125-138. 1982.

PRICE, Henry H. Hume's Theory of The External World. Oxford: Oxford University Press. 1940.

STRAWSON, Galen. The Secret Connexion. Causation, Realism, and David Hume. Oxford: Oxford University Press, 1996.

STROUD, Barry. Hume. London and New York: Routledge, 1995.

YOLTON, John W. Perceptual Acquaintance from Descartes to Reid. Minneapolis: University of Minnesota Press. 1990.

WILSON, Fred. "Hume on Abstract Idea of Existence", in: Hume Studies, vol.xviii, n.3, p.167-201. 1991.

WRIGHT, J.P. "Hume's Academic Scepticism: a Reappraisal of His Philosophy of Human Understanding". In: Critical Assessments (Hume), vol.II, p. 222- 247. 1995. 